\title{
Predicting Psychological Empowerment Among Service Workers: The Effect of Support-Based Relationships
}

\author{
David L. Corsun \\ Washington State University \\ Cathy A. Enz \\ Cornell University
}

\begin{abstract}
Data from 292 service workers in 21 private clubs show that supportive peer and customer relationships are predictive of higher levels of employee experienced empowerment. Both organizational and employee-customer relationships accounted for significant variation in the dimensions of empowerment: meaningfulness, influence, and self-efficacy. Beer helping and supportive customer relationships were the two most influential predictors of all three empowerment dimensions. Implications for future research and for management practice are discussed.
\end{abstract}

\section{Introduction}

In a competitive environment in which organizations must be faster, leaner, provide better service, be more efficient, and ultimately more profitable, an empowered, and proactive workforce is thought to be essential (Block, 1987; Bowen \& Lawler, 1992; Fulford \& Enz, 1995; Sparrowe, 1995). Bowen and Schneider (1985) argue that the manager-employee relationship be altered in service industries to reflect the impact of the relationship between service workers and customers. The underlying theme inherent in their specific recommendations is that an empowered workforce is better able to provide high quality customer service. Thus, a source of competitive advantage capable of differentiating an organization from others is its people and how they work. Pfeffer (1994) notes that achieving competitive success through people means working with them, not limiting the scope of their activities. Recent evidence that workers whose managers are perceived as supportive are more likely to see themselves as influential (Keller \& Dansereau, 1995; Parker \& Price, 1994) supports this notion. A new partnership between management, customers, and employees based on honesty, trust, caring, support, dignity, and mutual respect is at the heart of employee experienced empowerment (Melohn, 1994).

In this paper, we present the results of a study of the impact of support-based relationships on the level of perceived employee empowerment of service workers in private 
country clubs. The supportive relationships of interest in this study include both internal organizational relationships with co-workers and management, and customer relationships. This sample provides an excellent opportunity to explore a consistent set of relationships in a service setting, particularly the employee-customer relationship. Supportive relationships within the work environment and with customers are argued to positive^ ${ }^{\wedge}$ shape experienced empowerment

\section{The Importance of Support-based Relationships}

It has long been known that the environment people work in can shape their attitudes and behaviors in either positive or negative ways (Katz \& Kahn, 1978). At the heart of workers' daily lives are their relationships with the customers, the organization, and their co-workers. These relationships create a particular reality that guides and directs employees. Work environments fostering support-based relationships, defined here as relationships which are characterized by helping, participation, trust, and/or involvement, are argued to result in worker empowerment.

People value "a sense of community" (Schneider, Gunnarson, \& Niles- Jolly, 1994, p. 23) and cooperation among their co-workers (Locke, Schweiger, \& Latham, 1986). From their supervisors and the organization more generally, people desire consideration and respect (Locke, Schweiger, \& Latham, 1986). They seek mutual commitment in the form of relationships ruled by more than economic interests (Grenny, 1993). Given the high degree of consumer participation in the production of services, the nature of the employee-customer relationship can empower or enslave the worker (Schneider, Gunnarson, \& Niles-Jolly, 1994). An environment of fear and distrust breeds lost pride and self-protective behaviors among workers (Ryan \& Oestreich, 1991). In contrast, when working in a positive environment based on supportive and caring relationships with co-workers, the organization and the customer, it is likely workers will be more empowered.

When service workers, many of whom are minimum wage and/or seasonal, are treated as a cost to be minimized or avoided, the employment relationship may be stuck in what Block (1987) calls the bureaucratic cycle. In these relationships, employees submit to authority and are denied selfexpression. The outcomes for workers are feelings of dependence and helplessness that make it difficult for them to provide an extraordinary response to customer needs. In these unsupportive environments, fear and turnover are both high. Fear of separation from others is what Harvey (1988) believes causes people to be suspicious, avoid risks, and withdraw from responsibility. He argues that we have not learned how to "connect" with others, and that we become trapped in loneliness. Bellah and his colleagues indicate that "the problem is not so much the presence or absence of a "work ethic' as the meaning of work and the ways it links, or fails to link, individuals to one another" (Bellah, Madsen, Sullivan, Swidler, \& Tipton, 1996, p. 56). If disconnection from others leads to loneliness, helplessness, and depression, it is plausible to consider that supportive, connecting relationships can lead to psychological empowerment. 


\section{A Definition of Empowerment}

Empowerment is fundamentally a motivational process of an individual's experience of feeling enabled. While many have focused discussion of empowerment on situational attributes or management practices addressing what an organization can and should do to dehumiliate work and "release hidden resources" (Carlzon, 1987), psychological empowerment focuses on employee experience and, specifically, intrinsic task motivation (Thomas \& Velthouse, 1990). Inherent in the notion of psychological empowerment is the understanding that reality is socially constructed. In contrast, the program-based, structural view-empowerment as objective reality-fails to account for the biases inherent in perception (Jones, 1990). Neither the "good" intentions nor job redesign efforts of management can assure experienced empowerment. Rather, workers' interpretations of these intentions and actions - their perceptual realities - are what matter (Spreitzer, 1996).

To empower is to give power, so one dimension of empowerment is the degree to which individuals have personal influence or choice regarding their own behavior. Personal influence is experienced when an employee believes she or he can, through self-determined behavior, affect organizational results. Another aspect of enabling is feeling "able" to perform the work competently, called self-efficacy. Feelings of self-efficacy are rooted in the individual's belief that she or he is capable of performing work activities with skill and success, and are considered task specific (Gist, 1987). A final dimension of empowerment is that employees find meaningfulness in their work, or believe in and care about what they do. An empowered person views the goals and objectives associated with her or his work activity as consequential. These three dimensions, personal influence, self-efficacy, and meaningfulness, are the critical components of an empowered worker. These three dimensions of empowerment have been developed and validated in both manufacturing (Spreitzer, 1995) and service contexts (Fulford \& Enz, 1995).

While many have used the term empowerment, the definition and three dimensions defined here provide a systematic psychological, motivation-based approach to the construct. In keeping with the careful conceptualization offered by Spreitzer $(1992,1995,1996)$, this view of empowerment is limited to the work domain.

This multidimensional view of psychological empowerment is related to, though different from, Job Characteristics Theory (Hackman \& Oldham, 1980). The job characteristics model describes work redesign and enrichment, through the alteration of specific attributes of a job, such as the degree to which the job has a variety of different activities, requires completion of a whole, or has an impact on the work of others. Hackman and Oldham (1980) indicate that altering job characteristics will foster an enhanced psychological state. They further note that individuals will vary in the degree to. which change in job design affects their psychological state. The kinds of redesign the job characteristics model calls for are compatible with the structural, programmatic efforts management has been calling empowerment for over a decade. These practices conform with what Quinn and Spreitzer (1997) term the mechanistic 
model of empowerment Inherent in the mechanistic model is the "incorrect assumption ... that empowerment is something managers do to their people" (Quinn \& Spreitzer, 1997, p. 41). However, whether an individual perceives her- or himself as empowered is, as we have already argued, a function of perception. In addition, we argue that empowerment as a psychological state exists as a result of factors other than structural change or work redesign.

The dimensions of empowerment described above somewhat resemble components of Hackman and Oldham's (1980) model. Meaningfulness, for example, maps onto their "meaningfulness of work." Self-efficacy bears similarity to "knowledge and skill"; however, Hackman and Oldham (1980) "refer to objective knowledge and skills ... where "knowledge and skill' is an individual difference moderator" (Spreitzer, 1996, p. 484) whereas selfefficacy is an individual's perception of competence and the likelihood of successful task completion. Finally, influence is related to autonomy, however, this empowerment dimension subsumes the related notions (in service environments) of self-determination and impact-the ability to guide "strategic, administrative, or operating outcomes at work .... No element of the job characteristics framework is consistent with the impact dimension" (Spreitzer, 1996, p. 484) described above. Finally, rather than assessing the "more objective, job-oriented characteristics and individual differences developed by Hackman and Oldham (1980)" (Spreitzer, 1996, p. 484), the empowerment dimensions measure workers' cognitions. This approach assumes that individuals can have varying degrees of empowerment, from more to less, rather than being either empowered or not empowered. This view allows that psychological empowerment is possible in the absence of systematic programs of empowerment. In this paper, we focus on the cognitions of service workers, not on management practices.

\section{Power and Empowerment}

Both the psychological and structural views relate, as the word "empowerment" indicates, to power and control in organizations. It has long been argued that the routinization (Marx, 1844) and de-skilling of work (Braverman, 1974) strip workers of the power associated with the thinking and planning aspects of work. The Industrial Revolution changed the balance of power in the workplace-work processes were no longer controlled by skilled craftspeople; managers and machines took over (Brecher, 1978). Marx (1844) argued that work had become dehumanized, and workers had become alienated from their work. Empirical evidence supports the notion that routinization reduces worker power (Kipnis, 1984).

Kipnis (1984) indicates that managers, who are high power actors, may influence worker behavior through the use of either strong or weak power tactics.

Tactics of influence refer to the actual means used by powerholders to change the behavior of target persons.... Strong tactics of influence are those that are perceived by powerholders as not allowing the target person freedom to decide whether to comply, without incurring severe costs. (Kipnis, 1984, p. 130) 
Such tactics are used quite overtly. Strong tactics, which relate to an authoritarian management style, derogate the low power actor. The successful use of strong power tactics by a manager will, over time, engender an increasingly negative view of the work setting on the part of the employee. In contrast, weak means of influence are unobtrusive and are not associated with any obvious costs (Kipnis, 1984). Empowerment programs, though often "packaged" as management's effort to return power and control to the worker, may be viewed as weak tactics of influence.

Power distribution may be viewed from one of two basic viewpoints, fixed sum or expandable pie. When viewed through the lens of influence tactics, programmatic empowerment conforms with an expandable pie view of power-the more one gives away, the more one has. Thus, programmatic empowerment provides management with several concomitant benefits, among which are reduced conflict, and greater management power and

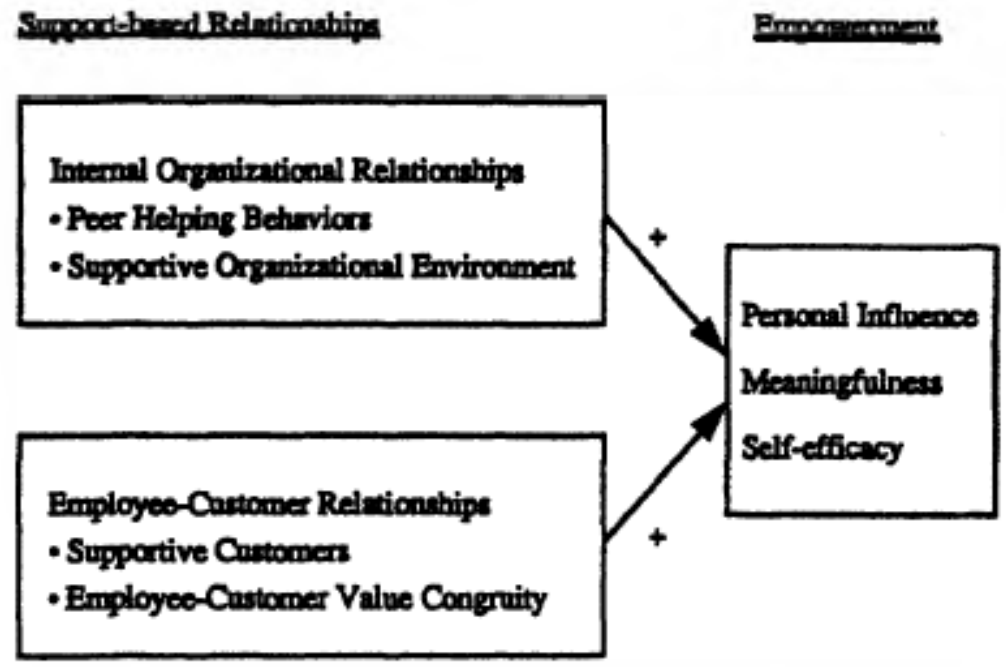

\section{Fig. 1. A model of the linkage of support-based relationships and empowerment.}

control. According to Lukes' (1974) "radical view" of power, manipulating workers' wants - in the form of programmatic empowerment-in order to prevent conflict, is an insidious exercise of power.

The support-based relationship model of empowerment we present and test below, although it includes a weak tactic of management influence-the creation of a' supportive work environment-emerges out of individuals' naturally occurring perceptions and evaluations of workplace relationships. 


\section{A Support-based Relationship Model of Empowerment}

Figure 1 shows a model of the linkage between various aspects of support-based relationships and the three dimensions of empowerment defined above. As the model shows, relationships have been placed in two broad categories, those that involve the organization or its members and those that transpire with the customer.

\section{Internal Organizational Relationships}

One indicator of supportive and strong relationships is the willingness of employees to help each other. Helping or prosocial behaviors of interest here are functional or positive activities, not those that sabotage the organization (Brief \& Motowidlo, 1986). Helping behaviors are those actions employees are willing to engage in, beyond their job requirements, that benefit both the peer target of the behavior and the organization (Brief \& Motowidlo, 1986; Dovidio, 1984). As such, helping behavior is a measure of being a supporter of others.

In their review of the prosocial organizational behavior literature, Brief and Motowidlo (1986) identified several contextual and individual correlates of such activity. Prosocial behavior was found to be associated with participation in decision making, the perception of proficiency, and several conditions affiliated with one's work role. Van Dyne and her colleagues (1994) provide evidence that covenantal relationships mediate the relationship between what have typically been viewed as antecedents of organizational citizenship behaviors, which are essentially synonymous with prosocial behaviors, and the citizenship behaviors themselves. "A covenantal relationship is based on commitment to the welfare of both parties to the exchange and is also based on values" (Mm Dyne, Graham, \& Dienesch, 1994, p. 769). Peers who help one another empower through their support and by providing others with the opportunity to reciprocate. Covenantal, support-based relationships, as evidenced by peer helping behaviors, help humanize the work environment. It is argued, therefore, that helping behavior is an important ingredient in the prediction of employee perceptions of personal influence, selfefficacy, and meaningfulness. Hypothesis la is offered in light of this prediction.

Hypothesis la. Helping behaviors from peers will be positively associated with service workers' experienced empowerment.

Supportive organizational environments are those in which the organization actively establishes a workplace setting described as supportive, trusting, caring, participative, and generally relationship-oriented. Managers who attempt to engender supportive environments are typically characterized as humanistic. They believe that an appropriate work environment allows workers to reach their full potential (Organ \& Bateman, 1991). As such, humanistic managers endeavor to positively manipulate the environment so as to increase worker productivity and satisfaction. Previous research has shown that managerial support is associated with worker perceptions of influence (Keller \& Dansereau, 1995; Parker \& Price, 1994). 
A supportive organizational environment represents employees' characterizations of the organization vis-h-vis cultural norms. Previous work in hospitality settings has found the relationship between the organizational culture and empowerment to be positive (Sparrowe, 1994,1995; Fulford \& Enz, 1995). When a work environment is viewed as supportive, employees are energized and more likely to experience empowerment. This relationship is stated formally below.

Hypothesis Ib. A supportive work environment created by the organization will be positively related to service workers' experienced empowerment.

\section{Employee-Customer Relationships}

The service worker's relationship with the customer is also critical in determining the degree to which empowerment is psychologically experienced. When customers respect and dignify the worker, the likelihood of that individual experiencing empowerment is enhanced. The reciprocal nature of this relationship would suggest that workers treated with respect and appreciation would be more likely to provide caring and meaningful service to the customer.

The service worker performs emotional labor and must adhere to display rules with regard to expressing emotions apropos of a service relationship (Hochschild, 1983). Qualitative research examining service provider-consumer relationships has indicated that service workers use positive emotional displays to maintain control in their exchanges with customers (Bigus, 1972; Mars \& Nicod, 1984; Whyte, 1946). More recent quantitative work by Rafaeli and Sutton (1990) provides support for the earlier qualitative findings. As stated formally in Hypothesis $2 a$, we propose that customer displays of support and respect for the service worker enhance the service workers' perceived control of the situation and, thereby, her or his experienced empowerment

Hypothesis 2a. Customer supportiveness will be positively associated with service workers' experienced empowerment

Workers are likely to prefer the organization to be run such that they are able to easily and effectively perform their work in a pleasant secure work environment They are also liable to experience meaningfulness and influence in their work when they view the customer as sharing these fundamental values and beliefs. Further, value congruity is particularly important in the context of private clubs because customers are likely to have a more significant effect on the work setting given the permanence of their membership status. Rather than the often surveyed single-purchase consumer, customers in a private dub setting represent repeat customers, a consumer population with a vested interest in the organization's success. The values and beliefs of this customer group are likely to shape how the organization functions more directly than organizations where customers are not repeat or dedicated service users.

Perceptions of support from customers should be more likely when value congruence or sharing of beliefs exists between the customer and service employee regarding how the 
operation should be run. Workers may seek value congruence with customers to boost or maintain self-esteem. Empowerment, when defined as enabling, is related to perceptions of selfworth (Conger \& Kanungo, 1988). Agreement produces likeness that facilitates enabling. Work settings with high value congruence may trigger a Pygmalion effect (Eden \& Ravid, 1982; Eden \& Shani, 1982), resulting in greater self-efficacy, meaning, and influence perceptions among workers. The next hypothesis summarizes the proposed relationships between value sharing and empowerment.

Hypothesis $2 b$. Employee-customer value congruity will be positively related to service workers' experienced empowerment.

In srim, the hypotheses argue that supportive workplace relationships will be positively associated with psychological empowerment The existence of supportive relationships among co-workers, the organization and its employees, and the customers and the employees will be enabling. Service workers in these positive relationships will experience higher levels of meaningfulness, personal influence, and self-efficacy.

\section{Method}

\section{Data Collection}

Data were collected from 292 service employees in 21 private clubs whose general managers participated in an executive program at a northeastern university. Although all the executives were familiar with the concept of empowerment, none of their operations had formal empowerment programs in place. Surveys were sent to each general manager for distribution to employees in advance of the executive program. Clubs were located throughout the United States with the East (North and South combined) being the best represented of the regions (60\%). Of the 292 respondents, $78 \%$ worked full time and the remaining $22 \%$ were parttime workers. Respondents were almost evenly distributed between males (56\%) and females (44\%).

Private clubs were selected as data gathering sites in part because of the nature of these service organizations. The range of products and services offered and the customer/member clientele are both fairly stable for a given club. Rather than system or process altering strategic change, clubs are characterized by an intense focus on critical service execution on gradually evolving member service preferences. Thus, change occurs more at the encounter levelbetween the service worker and the member-than at a strategic level. ITie service employee is, therefore, relied upon not only for service provision but for the informal gathering of customer preference data.

Based on the description above, it would seem appropriate to design programs to empower service workers in club settings. However, other industrywide characteristics of service organizations make programmatic empowerment difficult. While the service encounter is critical and the customer base stable, country clubs tend to experience very high levels of 
turnover. Among the distinguishing features of the industry are low wages, variable work schedules, and a reliance on seasonal, permanent part-time, and temporary workers. Reliance on a minimum wage and temporary labor force in private clubs, coupled with the status bifurcation between service workers on the one hand, and management and customers on the other, discourages the instituting of formal empowerment programs. This tension between organizational and member stability and employee flux provides an interesting backdrop for studying psychological empowerment.

\section{Measures}

Empowerment was measured using a 12-item scale originally developed by Spreitzer (1992, 1995), and modified for service environments by Fulford and Enz (1995). Participants recorded their responses to the items on a 7-point Likert scale ranging from 1, "strongly disagree," to 7, "strongly agree." In an application of the scale to service organizations (Fulford \& Enz, 1995), factor analysis revealed three distinct dimensions of empowerment: meaningfulness, personal influence, and self-efficacy. The service derived dimensions will be used in this study because of their appropriateness for this service context.

The meaningfulness dimension of empowerment is derived from the three items measuring the degree to which employees find fulfillment in what they do.. Those whose jobs are high in meaningfulness experience fit between.'their work and their values. The reliability coefficient for this subscale (Cronbach's alpha) was .79 for this study. Personal influence measures an employee's belief that she or he affects work processes and decisions. Specifically, workers who perceive themselves as influential believe they have significant control in their job and work group. This six item component of empowerment had a reliability coefficient (Cronbach's alpha) of .78. The final dimension of empowerment measured was self-efficacy. This measure captures an employee's perception that she or he possesses the skills required to be successful on the job and is likely to achieve that success. Self-efficacy includes both perceived competence and confidence. In this study, a reliability coefficient (Cronbach's alpha) of .68 was found for this three-item subscale.

\section{Support-based Relationships}

Two measures of organizational relationships were used as independent variables in this study. These measures were selected because of their high construct validity and reliability in previous research.

Peer helping behavior was assessed using a 7-point Likert scale. The five-item scale, adapted from the altruism subscale of the organizational citizenship behavior scale (Bateman \& Organ, 1983) and the literature on prosocial behavior (Brief \& Motowidlo, 1986), reflects an employee's willingness to engage in extra-role behaviors that benefit the organization and the direct beneficiary of the help. Cronbach's alpha was .75 for this measure, suggesting a high level of scale reliability. 
Supportive organizational environment was captured by asking employees how accurately their organization was described by each of five characteristics indicative of support. The items, measuring perceptions of trust, participativeness, and employee and relationship orientations, were scored on a scale ranging from "does not describe my club," to "describes my club completely." A reliability (Cronbach's alpha) of .77 was found for this scale.

\section{Customer Relationships}

Customer supportiveness and employee-customer value congruity were the two measures used to capture the employee-customer relationship. Customer supportiveness reflects the degree to which the customers as a group are supportive of the employees. Supportive customers are described as trusting, open, and friendly. Using a 5-point Likert-type scale, respondents indicated how closely each of four characteristics corresponded with their view of club customers. Response options ranged from a low of "does not describe club customers" to a high of "describes club customers completely." The reliability coefficient (Cronbach's alpha) for this scale was .85.

Employee-customer value congruity was measured using the 20-item Enz (1986) organizational value congruence scale. This scale measures the degree of value similarity employees express with the customers of the club regarding how the organization should be run. Issues such as professionalism, service and quality, profits, and community involvement are specific values for comparison in the scale. The items were scored on a 7-point Likert-type scale from a low of 1, "very dissimilar to customers," to a high of 7, "very similar to customers." This predictor had a reliability coefficient (Cronbach's alpha) of .93 for this study, consistent with the reliability of this scale in other service contexts (Enz, 1986).

Following the procedure employed by Schriesheim (1979) and Podasak- off and his colleagues (Podsakoff, Todor, Grover, \& Huber, 1984), we performed Hannan's one factor test (1967) to determine the presence of common method variance bias. All seven variables, the three empowerment dimensions and the four hypothesized antecedents, were entered into a principal components factor analysis with varimax rotation. According to this technique, if a single factor emerges from the factor analysis or one "general" factor accounts for over $50 \%$ of the covariation in the variables, common method variance is present. Our analysis revealed a two-factor structure with each factor accounting for $31 \%$ of the variability. Thus, no general factor was apparent While this analysis does not completely rule out the possibility of common method bias, it does provide some post hoc statistical support for the absence of such bias in the findings presented below.

\section{Results}

Table I shows the descriptive statistics, scale reliabilities, and correlation matrix for the support-based relationship and empowerment variables. The results indicate that strong, positive relationships exist between the work environment variables and dimensions of empowerment. Most notable are the relationships between peer helping behaviors and 
employee perceptions of meaningfulness, personal influence, and self-efficacy. While the intercorrelations for several of the indicators of support-based relationships in the work environment were high, they were not so large as to raise issues of conceptual overlap. The Cronbach alphas for all of the scales suggest strong internal reliability for the measured constructs.

To explore the connection between support-based relationships and the three dimensions of empowerment, three independent regression models were devised. The results of these three independent linear regression analyses are presented in T\&ble II. All three models were significant $(p<.001)$. The variance in the dimensions of experienced empowerment explained by the support-based relationship variables ranged between $20-30 \%$ percent In general, then, supportive relationships are empowering for service workers.

Comparing the beta coefficients in each model reveals peer helping behaviors to have the largest effect on experienced empowerment Peer helping behaviors were significant predictors of meaningfulness, personal influence, and self-efficacy, providing unequivocal support for Hypothesis la. Significant evidence was also found for Hypothesis 2a. Customer supportiveness was the second most important predictor variable in the models, significantly predicting all three empowerment dimensions. Hypotheses $\mathrm{lb}$ and $2 \mathrm{~b}$ were not supported; $\mathrm{a}$ supportive organizational environment and employee-customer value congruity did not significantly predict any of the three empowerment dimensions.

\section{Discussion}

This study revealed that service workers' perceptions of experienced empowerment are greater when peer helping and customer supportive relationships exist. These significant relationships hold for each of three dimensions of empowerment-meaningfulness, influence, and self-efficacy.

Can workers perceive themselves as empowered in the absence of a formal empowerment program? If the behaviors of co-workers and customers convey support the answer is clearly yes. Given these data, it appears the probability of success of a programmatic Table I.'Means, Standard Deviations, Reliabilities, and Correlations: Facets of Support-Based Relationships and Empowerment

\begin{tabular}{|c|c|c|c|c|c|c|c|c|c|c|}
\hline & \multirow[b]{2}{*}{ Mean } & \multirow[b]{2}{*}{ SD } & \multirow[b]{2}{*}{$\alpha$} & \multicolumn{7}{|c|}{ Correlations } \\
\hline & & & & 1 & 2 & 3 & 4 & 5 & 6 & 7 \\
\hline $\begin{array}{l}\text { Support-based relationships } \\
\text { 1. Peer helping behaviors } \\
(n=289)\end{array}$ & 28.00 & 4.34 & .75 & & & & & & & \\
\hline $\begin{array}{l}\text { 2. Supportive organizational } \\
\text { environment }(n=277)\end{array}$ & 11.18 & 4.00 & .77 & .08 & & & & & & \\
\hline $\begin{array}{l}\text { 3. Customer supportiveness } \\
(n=285)\end{array}$ & 13.72 & 3.19 & .85 & $.15^{* *}$ & $.46 * * *$ & & & & & \\
\hline $\begin{array}{l}\text { 4. Employee-customer value } \\
\text { congruity }(n=262)\end{array}$ & 103.34 & 22.35 & .93 & $.23^{\circ * 4}$ & $.53^{\bullet \bullet \bullet}$ & $.44^{* 4 *}$ & & & & \\
\hline $\begin{array}{l}\text { Experienced empowerment } \\
\text { 5. Meaningfulness }(n=292) \\
\text { 6. Personal influence }(n=285) \\
\text { 7. Self-efficacy }(n=288)\end{array}$ & $\begin{array}{l}18.12 \\
30.21 \\
18.93\end{array}$ & $\begin{array}{l}2.99 \\
6.55 \\
2.23\end{array}$ & $\begin{array}{l}.79 \\
.78 \\
.68\end{array}$ & $\begin{array}{l}.51^{* * *} \\
.41^{* * * *} \\
.44^{* * *}\end{array}$ & $\begin{array}{l}.23^{* * *} \\
.29^{* * *} \\
.02^{\bullet}\end{array}$ & $\begin{array}{l}32 * * * \\
35^{* * *} \\
.15^{* *}\end{array}$ & $\begin{array}{l}.27 * * * \\
.33^{*} * \bullet \\
.18 * * \\
\end{array}$ & $\begin{array}{l}37^{* * *} \\
35^{* * *}\end{array}$ & $.24^{* * * *}$ & \\
\hline
\end{tabular}

$\boldsymbol{n}$ ranges from 248 to 288 for correlations using pairwise deletion of missing cases.

$p \leq 0.05$.

$\bullet p \leq 0.01$.

$* * p \leq 0.001$. 
Table II. Full Sample Regression Analyses: Support-Based Relationship Variables Regressed on Dimensions of Experienced Empowerment

\begin{tabular}{|c|c|c|c|}
\hline \multirow[b]{2}{*}{ Support-based relationships } & \multicolumn{3}{|c|}{ Dimensions of experienced empowerment } \\
\hline & $\begin{array}{l}\text { B Meaning- } \\
\text { fulness }\end{array}$ & $\begin{array}{l}\boldsymbol{\beta} \text { Personal } \\
\text { influence }\end{array}$ & B Self-efficacy \\
\hline $\begin{array}{l}\text { Peer helping behaviors } \\
\text { Supportive organizational environment } \\
\text { Customer supportiveness } \\
\text { Employee-customer value congruity } \\
\text { Adjusted } R^{2} \\
F\end{array}$ & $\begin{array}{l}.44^{* * \bullet} \\
.06 \\
.19^{* *} \\
.06 \\
.30 \\
26.32^{* \cdots *}\end{array}$ & $\begin{array}{l}.30^{* * *} \\
.09 * \\
.22^{* * *} \\
.12 \\
.25 \\
20.17^{* * *}\end{array}$ & $\begin{array}{l}.44^{* * *} \\
-.13 \\
.14^{* *} \\
.10 \\
.24 \\
20.17^{* * *}\end{array}$ \\
\hline
\end{tabular}

empowerment effort may be enhanced if workers' relationships with one another and with customers are supportive and community building. If an organization seeks to reap the benefits of employee empowerment such as enhanced quality or productivity, .but cannot afford to develop and institute a formal program, fostering supportive and helping co-worker and customer relationships may yield empowerment at relatively low cost to the organization. This finding is particularly useful for service organizations in which high seasonality of employment, and thus high turnover, make programmatic efforts more costly and difficult to implement Future studies might consider the possibility that empowerment programs without supportive helping relationships may fail to yield empowerment Examining relationships in concert with empowerment program design could be a fruitful area for future study.

Helping or prosocial behavior had the most profound impact in this study, suggesting that an environment in which good organizational citizenship is present contributes to psychological empowerment. People who help others, empower themselves. We suggest that if an organization seeks to empower employees and can do only one thing, management should facilitate the creation of an environment in which workers are encouraged to assist others and take positive action beyond the limits of their proscribed organizational roles.

The effects of a strongly prosocial culture are not felt only by individual members of the organization. As members' self-efficacy grows, so does the collective efficacy of the group (Bandura, 1986). Strong, positive perceptions of self and collective efficacy may result in greater effort to succeed and an increased likelihood that the effort is sustained when barriers to success are present (Bandura, 1986).

It may be that the relationship between peer helping behavior and efficacy is symbiotic and feeds on itself. As one experiences in-role success, feelings of high self-efficacy result. These feelings may increase the likelihood that one engages in extra-role helping behavior. The experience of success, or enactive attainment, influences positive efficacy perceptions more powerfully than any other source of information (Bandura, Adams, \& Beyer, 1977; Biran \& Wilson, 1981). Possibly, experiencing success when going beyond the scope of one's job affects 
efficacy perceptions more profoundly than in-role successes. If so, it is logical that, when one experiences extra-role success, the likelihood of engaging in helping behavior increases. Since perceptions of self and collective efficacy are good predictors of future performance, one might expect to find the quality of employee performance improving as perceptions of efficacy increase. In short, fostering a culture of helping and support may increase perceptions of empowerment which in turn reinforce the helping cultural values.

It is interesting to note that the level of organization based support, described as trusting, participative and supportive work environments did not strongly relate to service workers' experienced empowerment. It may be that workers perceive institutional efforts to create a supportive organizational environment as motivated by self-interest rather than genuine concern for the workers' welfare. In such cases, the manager-worker relationship may not be perceived as covenantal. Rather, workers may see themselves as engaged in a social exchange relationship. Workers may see organizational attempts to engineer the environment, even in a positive way, as manipulative. Under such circumstances, one is unlikely to view humanistic managers as giving honestly of themselves. Relatedly, the notion that the environment is management controlled may induce a heightened awareness of the difference in status between managers and line workers. This awareness may be accompanied by a corresponding belief that one is being patronized or treated paternalistically by management. Certainly, such negative perceptions can hardly be expected to engender feelings of empowerment.

The findings regarding employee-customer relationships indicate that employees place greater importance on maintaining civil, respectful relations with customers than on sharing their values. Given the traditional status hierarchy that exists in the typical country club environment, with customers atjfhe top, managers in the middle, and line workers at the bottom, the importance of customer support is not surprising. Producing and providing a service for hostile, rather than supportive customers, may accentuate the traditionally bifurcated status relations between club workers and customers. Such a situation may induce feelings of servility in the worker, resulting in psychological disempowerment. In contrast, supportive customers provide service workers with feelings of greater control and, thereby enable psychological empowerment

Value sharing between employees and customers is not related to service workers' experienced empowerment Although workers may espouse values congruent with customers in how the operation should be run, their values may actually be discrepant When asked to rank the five most important values, customers more often selected values regarding the maintenance of the operation over time and the development of new services, while employees identified high morale and employee satisfaction as value priorities. Hence employees and customers may not need to share similar values for employees to experience empowerment. 
Whereas we expected value congruity to enhance workers' feelings of support from customers, it may be that customers are supportive because, whether the workers share them or not, they deliver on the customers' values. Customer support then, may also be viewed as self-interested rather than altruistic. Club customers may simply be practicing noblesse oblige, showing respect in ways that reinforce the status images they have of themselves and the workers. It may well be that in more complex, professionalized service jobs such as financial services or insurance, value congruity is more likely to occur and be empowering. In such cases, the social status of the service provider is much closer, if not equal to, the service consumer's. The role of value congruity between workers in higher status occupations and their customers should be addressed in future research.

\section{Limitations of the Study}

This study, based on data from 21 different clubs from across the country, permits us to make limited inference to other clubs. It is possible that bias was introduced through the use of a convenient sample. However, the inference limitations are mitigated somewhat by the multisite data collection. Although clubs are similar to other types of leisure services, we can infer only with caution from our results to other types of service firms. However, support from similar findings regarding the relationship between culture and empowerment in other types of service firms (Sparrowe, 1995) serves to further alleviate our inferential limitations. Future studies should seek to include other types of service firms in the sample to gain a clearer picture of empowerment across service industries.

A second limitation of this study is the lack of multimethod operationalizations and measurements of the response variables, although this too is mitigated in part by the strong reliabilities of the measured variables. Future studies would benefit by employing alternative methods of assessing the dimensions of empowerment and sampling from organizations with and without formal empowerment programs. Conceptual replication will lend more credence to these and past results than would a repetition using the methods employed herein.

Last, all the constructs are measures of employee perceptions that may magnify the relationship between predictor and response variables. However, Harman's one-factor test (1967) for common method variance failed to reveal a general factor. Further, it is worth noting that there is no better source for the perceptions of workers than the workers themselves. Relatedly, the problem of common method bias when dealing with self-report, perceptual data has, at the very least, been overstated in the literature and may be fictitious (Crampton \& Wagner, 1994; Spector, 1987). Once again, the inclusion of multiple data locations and organizational cultures lessen the degree to which our results were affected. The analyses performed and the results reported reflect the perceptions of nearly three hundred people reporting on 21 different organizational environments. The above notwithstanding, the next generation of studies should attempt to gather information from alternative sources such as managers and customers. Despite these limitations, the data offer some preliminary insight into 
the power and potential of support-based relationships in enabling employees to experience empowerment.

\section{Conclusions}

Generally, we find the psychological empowerment of service workers to be higher when positive and supportive relationships exist with peers who are helpful and customers who are concerned. Experienced empowerment is not related to supportive institutional (management focused) relationships or the degree of espoused value agreement with customers. It may be that customers and managers who sincerely engage in supportive behaviors minimize the social status gap between the workers and themselves, thereby enabling workers to experience more meaningfulness, personal influence, and self-efficacy on the job.

Service organizations must not overlook the important role relationships play in employee perceptions of empowerment, lo improve the chances of success in structural empowerment efforts, supportive and helping relationships should be developed. Co-workers, customers, and management wquld do well to express and model supportive and helping behaviors. As these values come to be shared and lived, the qualify of work and service provided are likely to increase among employees.

Hence, a reason for the failure of empowerment efforts may be the lack of attention to creating relationship-based, supportive, and caring work environments. If so, then attention to work relationships as precursors to needed organizational structural changes may be essential. The positive relationship between customers' impressions of service quality and both workers' self-efficacy and job satisfaction, provide support for this perspective (Hartline \& Ferrell, 1996). This consideration is particularly appropriate in a country dub environment, wherein the consumer and service provider have a special relationship based on membership. Club customers are very much a part of the organization's culture.

While many executives talk about their empowered workforces little if any evidence of psychological empowerment is offered. Instead, many organizations have downsized middle managers and added responsibilities to the existing tasks of first-line workers. In many instances these redesigned jobs have failed to produce feeling of being empowered, but instead have created job stress, burnout, and helplessness. Many so called empowerment efforts are actions to flatten the organizational hierarchy and are motivated by short-term labor reduction strategies. These efforts lack grounding in a philosophical belief in enabling or empowering employees, and are not reinforced by strong communities based on supportive relationships. Efforts to reduce* hierarchy and enrich worker jobs may experience failure if the relationships are unsupportive, distrusting, abusive, or manipulative. Future studies should continue to explore the ways in which healthy and caring relationships can enhance organizational performance. 


\section{References}

Bandura, A. Social foundations of thought and action. Englewood Cliffs, NJ: Prentice-Hall, 1986.

Bandura, A, Adams, N. E., \& Beyer, J. Cognitive processes mediating behavioral change. Journal of Personality and Social Psychology, 1977, 35(3), 125-139.

Bateman, T S., \& Organ, D. W. Job satisfaction and the good soldier: The relationship between affect and employee "citizenship." Academy of Management Journal, 1983, 22, 783792.

Bellah, R. N., Madsen, R., Sullivan, W. M., Swidler, A, \& Tipton, S. M. The good society. New York: Vintage Books, 1996.

Bigus, O. E. The milkman and his customer: A cultivated relationship. Urban Life and Culture, 1972, 1,131-165.

Biran, M., \& Wilson, G. T Treatment of phobic disorders using cognitive and exposure methods: A self-efficacy analysis. Journal of Consulting and Clinical Psychology, 1981, 49(6), 886899.

Block, E The empowered manager: Positive political skills at work. San Francisco: Jossey-Bass, 1987.

Bowen, D. E., \& Lawler, E. E., III Total quality-oriented human resources management Organizational Dynamics, 1992,20(4), 29-41.

Bowen, D. E., \& Schneider, B. Boundary-spanning-role employees and the service encounter Some guidelines for management and research. In J. A Czepiel, M. R. Solomon, and C E Surprenant (Eds.), The service encounter Managing employee/customer interaction in service businesses. Lexington, MA D.C Heath and Company, 1985, pp. 127-147.

Braverman, H. Labor and monopoly capital- The degradation of work in the twentieth century. New York: Monthly Review Press, 1974.

Brecher, J. Uncovering the hidden history of the American workplace. The Review of Radical Political Economics, 1978, 10, 1-23.

Brief, A. R, \& Motowidlo, S. J. Prosocial organizational behaviors. Academy of Management Review, 1986, 11(4), 710-725.

Carlzon, J. Moments of truth. Cambridge, MA: Ballinger Publishing Co., 1987.

Conger, J. A., \& Kanungo, R. N. The empowerment process: Integrating theory and practice. Academy of Management Review, 1988, 13(3), 471-482.

Crampton, S. M., \& Wagner, J. A., III. Percept-percept inflation in microorganizational research: An investigation of prevalence and effect Journal of Applied Psychology, 1994, 79, 67-76. 
Dovidio, J. F. Helping behavior and altruism: An empirical and conceptual overview. In (Eds.), Advances in experimental social psychology (Vol. 17). New York: Academic Press, 1984, pp. 361-427.

Eden, D., \& Raved, G. Pygmalion versus self-expectancy: Effects of instructor- and selfexpectancy on trainee performance. Organizational Behavior and Human Performance, $1982,30,351-364$.

Eden, D., \& Shani, A. B. Pygmalion goes to boot camp: Expectancy, leadership, and trainee performance. Journal of Applied Psychology, 1982, 67(2), 194-199.

Enz, C. A. Power and shared values in the corporate culture. Ann Arbor, MI: UMI Research Press, 1986.

Fulford, M. D., \& Enz, C. A. The impact of empowerment on service employees. Journal of Managerial Issues, 1995, 7(2), 161-175.

Gist, M. E. Self-efficacy: Implications for organizational behavior and human resource management. Academy of Management Review, 1987, 12, 472-485.

Grenny, J. A culture of commitment. Executive Excellence, 1993, 10(2), 16.

Hackman, J/ R., \& Oldham, G. R. Work redesign. Reading, MA: Addison-Wesley, 1980.

Harman, H. H. Modem factor analysis. Chicago: University of Chicago Press, 1967.

Haktline, M. D., \& Ferrell, O. G The management of customer-contact service employees: An empirical investigation. Journal of Marketing, 1996, 60, 52-70.

Harvey, J. B. The Abilene paradox. Lexington, MA: Lexington Books, 1988.

Hochschild, A. R. The managed heart. Berkeley and Los Angeles: University of California Press, 1983.

Jones, E. E. Interpersonal perception. New York: W. H. Freeman and Company, 1990.

Katz, D., \& Kahn, R. L. The social psychology of organizations (2nd ed.). New York: Wiley, 1978.

Keller, T, \& Dansereau, F. Leadership and empowerment: A social exchange perspective. Human Relations, 1995, 48(2), 127-146.

Kipnis, D. Technology, power, and control. Research in the Sociology of Organizations, 1984, 3, 125-156.

Lawler, E. E. The ultimate advantage. San Francisco: Jossey-Bass, 1992.

Locke, E. A, Schweiger, D. M., \& Latham, G. P. Participation in decision making: When should it be used? Organizational Dynamics, 1986, 14(3), 65-79. 
Lukes, S. Power: A radical view. London: MacMillan.

Mars, G., \& Nicod, M. The world of waiters. London: George Allen \& Unwin, 1984.

Marx, K. Economic and philosophic manuscripts of1844. New York: International Publishers, 1964.

Meloth, T. The new partnership. New York: Wiley \& Sons, 1994.

Organ, D. W., \& Bateman, TS. Organizational behavior (4th ed.). Homewood, IL and Boston: Irwin, 1991.

Ouchi, W. G. The relationship between organizational structure and organizational control. Administrative Science Quarterly, 1977, 22, 95-113.

Ouchi, W. G. Markets, bureaucracies, and clans. Administrative Science Quarterly, 1980, 25, 129-141.

Parker, L. E., \& Price, R. H. Empowered managers and empowered workers: The effects of managerial support and managerial perceived control on workers' sense of control over decision making. Human Relations, 1994, 47(8), 911-928.

Pfeffer, J. Competitive advantage through people: Unleashing the power of the work force. Boston: Harvard Business School Press, 1994.

Podsakoff, R M., Todor, W. D., Grover, R. A., \& Huber, V L. Situational moderators of leader reward and punishment behaviors: Fact or fiction? Organizational Behavior and Human Performance, 1984, 34, 21*63.

Quinn, R. E., \& Spreitzer, G. M. The road to empowerment: Seven questions every leader should consider. Organizational Dynamics, 1997, 26, 37-49.

Rafaeli, A., \& Sutton, R. I. Busy stores and demanding customers: How do they affect the display of positive emotion? Academy of Management Journal, 1990, 53(3), 623-637.

Ryan, K. D. \& Oestreich, D. K. Driving fear out of the workplace, San Francisco: Jossey- Bass Publishers, 1991.

Schneider, B., Gunnarson, S. K., \& Niles-Joliy, K. Creating the climate and culture of success. Organizational Dynamics, 1994, 25(1), 17-29.

Scriesheim, G A. The similarity of individual directed and group directed leader behavior descriptions. Academy of Management Journal, 1979, 22(2), 345-355.

Sparrowe, R. T. Empowerment in the hospitality industry: An exploration of antecedents and outcomes. Hospitality Research Journal, 1994, 77(3), 51-73. 
Sparrowe, R. T. The effects of organizational culture and leader-member exchange on employee empowerment in the hospitality industry. Hospitality Research Journal, 1995, 18(3), 95109.

Spector, R E. Method variance as an artifact in self-reported affect and perceptions at work: Myth or significant problem? Journal of Applied Psychology, 1987, 72(3), 438-443.

Spreitzer, G. M. When Organizations Dare: The Dynamics of Individual Empowerment in the Workplace. Unpublished doctoral dissertation, University of Michigan, 1992.

Spreitzer, G. M. Psychological empowerment in the workplace: Dimensions, measurement, and validation. Academy of Management Journal, 1995, 38(5), 1442-1465.

Spreitzer, G. M. Social structural characteristics of psychological empowerment Academy of Management Journal, 1996, 35(2), 483-504.

Thomas, K. W., \& Velthouse, B. A. Cognitive elements of empowerment: An "interpretive" model of intrinsic task motivation. Academy of Management Review, 1990, 75(4), 666681.

Van Dyne, L., Graham, J. W., \& Dienesch, R. M. Organizational citizenship behavior Construct redefinition, measurement and validation. Academy of Management Journal, 1994, 37(4), 765-802.

Whyte, W. F. Human relations in the restaurant industry. New York: McGraw Hill Book CO., 1946. 